Victòria Alsina* and José Luis Martí*

\title{
The Birth of the CrowdLaw Movement: Tech-Based Citizen Participation, Legitimacy and the Quality of Lawmaking
}

https://doi.org/10.1515/auk-2018-0016

\begin{abstract}
One of the most urgent debates of our time is about the exact role that new technologies can and should play in our societies and particularly in our public decision-making processes. This paper is a first attempt to introduce the idea of CrowdLaw, defined as online public participation leveraging new technologies to tap into diverse sources of information, judgments and expertise at each stage of the law and policymaking cycle to improve the quality as well as the legitimacy of the resulting laws and policies. First, we explain why CrowdLaw differs from many previous forms of political participation. Second, we reproduce and explain the CrowdLaw Manifesto that the rising CrowdLaw community has elaborated to foster such approaches around the world. Lastly, we introduce some preliminary considerations on the notions of justice, legitimacy and quality of lawmaking and public decision-making, which are central to the idea of CrowdLaw.
\end{abstract}

Keywords: citizen participation, collective intelligence, CrowdLaw, crowdsourcing, decision-making, justice, legitimacy, new technologies, quality

\section{Introduction: The Birth of an Idea}

New technologies of information and communication are deeply transforming our politics, our governance, and our processes of lawmaking and public decisionmaking, as they are transforming everything else in human life. The Internet, mobile phone technology, artificial intelligence, machine learning, virtual reality, etc., they are all definitely creating new challenges and dangers for individual rights and democracy (Zittrain 2008; Morozov 2011; Bartlett 2018), but they also generate unprecedented opportunities for improving the legitimacy and, more generally, the quality of law and decision-making in our political systems (Noveck 2015; Noveck 2009; Benkler 2011; Benkler 2006; Bennett and Segerberg 2012), and

\footnotetext{
*Corresponding author: Victòria Alsina, Harvard University and The GovLab, e-mail: victoria_alsina@hks.harvard.edu *Corresponding author: José Luis Martí, Pompeu Fabra University of Barcelona, e-mail: joseplluis.marti@upf.edu
} 
the prospects for coordination and deliberation within and among social movements (Castells 2012; Tufekci 2017). In parallel, such legitimacy and quality of our democracies are being jeopardized by a growing socio-economic and political gap between the elites and the people, by an alarming decline in social trust and popular support towards political institutions, and by a subsequent and very dangerous re-emergence of populisms around the world (Putnam 2000; Mounk 2018; Foa/Mounk 2016).

One of the most urgent debates of our time is about the exact role that these new technologies can and should play in our societies and particularly in our public decision-making processes. A new concept, a new approach, and a new methodology, originally proposed by Beth Noveck, has emerged in the last year to tackle that debate, under the name of CrowdLaw (Noveck et al. 2017). And technologists, politicians, activists, civil servants, political philosophers, political scientists, and lawyers of all over the world are starting to study and support such new approaches.

CrowdLaw is the simple but powerful idea that parliaments, governments and public institutions work better when they boost citizen engagement, leveraging new technologies to tap into diverse sources of information, judgments and expertise at each stage of the law and policymaking cycle to improve the quality as well as the legitimacy of the resulting laws and policies.

CrowdLaw differs from many previous forms of political participation for six different reasons. In some of these respects, CrowdLaw widens the scope of such traditional forms of participation, still encompassing many of them. In others, it presents a narrower perspective that focuses on some particular elements of more general political participation. First, CrowdLaw is institutionalized direct participation and has the potential to impact how power is wielded, decisions are made and money is spent. It is conceptually connected to lawmaking and public decision-making of any kind and at any level, ranging from constitutionmaking, to legislation, to policy-making, and to judicial decision-making. Traditional forms of political participation were usually conceived either as mechanisms for aggregating and infusing direct inputs into the representative systemin the form of referendums, popular initiatives, and recalls-, or as indirect inputs of control over such representative system-such as lobbying campaigns, protests in the streets, or deliberation in the public sphere. CrowdLaw promotes direct engagement and participation, but it does it with the aim of enhancing the quality of law and public decision-making.

We owe to Jürgen Habermas the idea that the informal public sphere, and the non-institutional public deliberation and mobilization by and among citizens that takes place in it, is crucial for the legitimacy of our democracies, a necessary complement to electoral participation and the instruments of direct democracy men- 
tioned above (Habermas 1989[1962]). According to Habermas, such informal public deliberation must run in parallel to the formal deliberative decision-making processes internal to political institutions, such as the parliament, the executive, the regulatory agencies, and the judiciary. And, as he explicitly exposed in his own articulation of the 'two-track model', a healthy, legitimate, well-functioning democracy is one in which these two tracks of public deliberation -the institutional and the non-institutional- interact and intertwine also in a dialogical, argumentative way (Habermas 1996[1992]). CrowdLaw comprises a variety of forms in which ordinary citizens may directly engage in institutional deliberations and decision-making processes to contribute to their quality. In that sense, CrowdLaw helps to deepen such Habermasian interaction and mutual reinforcement and empowerment between citizens and institutions, precisely in a moment when the gap between them is widening and there is a growing break of trust, as well as an evident deterioration of the necessary conditions for a healthy democratic system in most developed democracies (Fung 2018).

Second, CrowdLaw focuses on obtaining expertise, experience, ideas and data instead of opinions. It is not merely a better form of opinion polling or aggregating preferences, but a way to bring collective intelligence to bear to solve problems (Noveck 2015; Landemore 2012; Sunstein 2006; Sunstein/Hastie 2014). Thus, CrowdLaw connects nicely with a deliberative ideal of democracy, one according to which complex and overlapping processes of public deliberation contribute to make better public decisions and increase political legitimacy through better forms of public information, mutual refinement of political beliefs and a reasoned transformation of political judgments based on argumentation (Habermas 1996[1992]; Bohman/Rehg 1997; Elster 1998; Besson/Martí 2006; Parkinson//Mansbridge 2012). True collective intelligence is much more than a mere aggregation of opinions or even judgments, as the proponents of aggregative or economic views of democracy may presuppose. It requires a collective process of mutual enlightenment and argumentation, one in which citizens and public institutions must interact dialogically, and can be measured by its epistemic merits, its capacity to make correct decisions (Habermas 1996[1992]; Besson/Martí 2006; Estlund 2007; Landemore 2012).

The third reason, related to the latter, is that CrowdLaw is not only interested in improving the legitimacy of law and public decisions by virtue of a fuller inclusion, by merely hearing more voices, or by ensuring a greater political equality, even if all these things might be important on their own. CrowdLaw's main focus is in the quality of the law and decisions made. It emphasizes the institutional design needed to digest all collected knowledge and put at the service of better decisions, not merely the design needed for individuals to participate. Thus, it is participation for the sake of a greater quality and effectiveness of the law and pub- 
lic decisions, not for participation's sake. Therefore, CrowdLaw endorses a more complex idea of democratic legitimacy, one that combines purely procedural elements with epistemic ones, and with the substantive quality of its outcomes.

Fourth, CrowdLaw processes generally involve ceding some real control over a given aspect of law and policymaking, at least in part, to a more diverse audience. It then implies opening up existing public decision-making processes to the collaboration of ordinary citizens. Thus, CrowdLaw constitutes the highest form of the ideal of Open Government. It implies a government that must be open to the much needed inputs of its citizens. And it therefore enhances the ideal of deliberative and participatory democracy as well, but one, again, that seeks participation not for participation's sake.

Fifth, CrowdLaw is any law or policy-making process that offers a meaningful occasion for the public to participate in one or multiples stages of the decisionmaking, diversifying the citizen engagement opportunities expanding them to each stage of the law and policymaking cycle, including but not limited to the processes of problem identification, solution identification, proposal drafting, ratification, implementation or assessment. Traditional forms of participations, like citizen initiatives or consultations, normally focus only on the early stages of this cycle without considering that enable channels of engagement to co-creation, coimplementation, and impact co-assessment of laws and policies can be also extremely fruitful in terms of improving their quality and effectiveness. In that respect, CrowdLaw expands the horizon of more traditional forms of citizen participation.

Finally, and very importantly, CrowdLaw must involve the use of a digital technology at the service of collective intelligence. There may be other ways in which citizens engage in enhancing the quality of lawmaking, policymaking or public decision-making in general. And they can also strengthen the quality and legitimacy of the laws, policies and decisions made. But if they do not use digital technology, it is not CrowdLaw. CrowdLaw is, by definition, tech-based. Even if technology, and this is central, is conceived only instrumentally, as a means to get the aim of collective intelligence and democratic legitimacy, not as a valuable end on itself.

These six differences between CrowdLaw and more traditional forms of political engagement and participation do not mean that CrowdLaw is entirely new. The name is new. ${ }^{1}$ The thing is not. Some varieties of citizen initiatives, some forms of participatory budgeting, some citizen councils and citizen assemblies may count

1 The term crowdlaw was coined by the Governance Lab at New York University in September 2014 in the framework of an international conference that convened practitioners linked 
as CrowdLaw as long as they meet the requirements. CrowdLaw offers, however, a new approach to systematize them all around elements that are seen as central for a better lawmaking and public decision-making.

CrowdLaw is beginning to bloom. A CrowdLaw global movement has born and a community of experts, politicians, public employees, NGOs and citizens engaged in implementing and promoting CrowdLaw experiences is rising. ${ }^{2}$ Around the world, there are already over 100 examples $^{3}$ of parliaments, governments and public institutions turning to the Internet and new civic technologies to involve the public at various stages of decision-making, from problem identification to solution identification, proposal drafting, ratification, implementation or evaluation. ${ }^{4}$

However, despite pockets of CrowdLaw innovation, parliaments, governments and public institutions are slow to implement public engagement, fearing that participation will be burdensome, at worst, and useless at best. Likewise, where an opportunity to participate exists, the public is not always informed or eager to do so, suspecting that participation will not be relevant and thereby exacerbating participation-fatigue and current record-setting levels of public distrust in government institutions. ${ }^{5}$

This paper and the following are a first attempt to introduce the idea of CrowdLaw and the movement behind it to the academic world. We will start, in the next section, by reproducing and explaining the CrowdLaw Manifesto that the rising CrowdLaw community has elaborated to foster such approaches around the world. After that, in section three, we will introduce some preliminary considerations on the notions of justice, legitimacy and quality of lawmaking and public

to parliaments around the world experimenting with tech enabled public engagement. See: http://thegovlab.org/crowdlaw-in-action-details-a-preview-of-next-weeks-online-event.

2 For more information about the CrowdLaw movement, as well as about any kind of events related to CrowdLaw, enter into the webpage: https://crowd.law.

3 The Governance Lab created a growing repository of more than 100 CrowdLaw cases from around the world that can be consulted online into the webpage: https://catalog.crowd.law.

4 Beth Noveck's article, following this one, presents and comments some of these selected examples and good practices of CrowdLaw today around the world. See Noveck, Beth Simone, CrowdLaw: Collective Intelligence and Lawmaking, in: Analyse \& Kritik 40(2).

5 According to the Eurobarometer 85 (2016) the proportion of Europeans who do not trust their national parliament $(65 \%)$, or their national government $(68 \%)$ increased in two percentage points since last year (See: https://ec.europa.eu/commfrontoffice/publicopinion/index.cfm/ResultDoc/download/DocumentKy/75902. Likewise, according to a recent poll by Gallup (2017) just $8 \%$ of people say they have a great deal of confidence in government, according to a recent poll by Gallup. See: https://www.npr.org/2018/01/17/578422668/heres-just-how-littleconfidence-americans-have-in-political-institutions. 
decision-making, which as we have seen are central to the idea of CrowdLaw. Finally, the next piece, by Beth S. Noveck, will review several existing experiences of citizen engagement in governance that are being implemented all over the world and constitute excellent examples of the kind of approach we are advocating here under the name of CrowdLaw.

We hope these two articles together will allow the reader to get a more precise understanding of what CrowdLaw is, why it is an attractive idea and approach to government and public decision-making that differs from previous ones, why we should care about the quality and legitimacy of such decision-making in that way, and how we can identify those processes of citizen participation that do count as CrowdLaw and those that does not.

\section{CrowdLaw Manifesto, Annotated}

The CrowdLaw Manifesto presented below is an international initiative led by The Governance Lab at New York University that brings together the nascent CrowdLaw community to establish the foundation of this movement. On March 13-17 2018, at the Rockefeller Foundation Bellagio Center, The Governance Lab convened a group of 20 international experts from diverse backgrounds to discuss the challenges, opportunities and the future of CrowdLaw. ${ }^{6}$ The CrowdLaw Manifesto comprises twelve statements, the initial draft of which was written, collaboratively, as the final product of that conference. The final objective of this CrowdLaw Manifesto is to booster the design, implementation and evaluation of new tech-enabled practices of public engagement in law and policymaking to create a 'race to the top'7 in CrowdLaw for mutual learning and collaboration and in support of more research in the field, as well as contribute to cohere a CrowdLaw global movement.

Here we present, elaborate, and comment on each of these twelve statements:

1 To improve public trust in democratic institutions, we must improve how we govern in the 21st century.

\footnotetext{
6 For more information about the Program of the Conference titled "CrowdLaw: People-led Innovation in Urban Lawmaking” organized by The Governance Lab at the Rockefeller Foundation Bellagio Center, see: https://crowd.law/crowdlaw-people-led-innovation-in-urban-lawmaking868dd31d32a2.

7 Race to the Top (RTT) is an emblematic US Department if Education competitive grant created to spur and reward innovation and reforms in state and local district K-12 education funded by the American Recovery and Reinvestment Act of 2009.
} 
We live in a world beset with ever more complex challenges-from the impacts of climate change to the humane delivery of services for refugees to issues arising from aging populations, terrorism, and increasingly unpredictable international relations and relationships in a context of highest global interdependency. Declining tax revenues and deteriorating fiscal conditions, coupled with increasing volatility of state financial support, have put significant financial pressures on governments, diminishing their ability to deliver those services they have traditionally provided-much less to adapt to changing times. Moreover, citizens' trust in the institutions tasked with addressing these public challenges is at an all-time low while, paradoxically, public expectations of what government should deliver have risen. Thus, there is a desperate need to ask and answer how we should redesign our governing practices to solve the complex policy challenges of the 21st century. This is not a political question of the choice between policies but fundamentally an inquiry into the mechanisms by which we make policy and deliver services in our cities in the public interest.

1. CrowdLaw is any law, policy or public decision-making process that offers a meaningful, tech-based opportunity for the public to participate in one or multiple stages of decision-making, including but not limited to the processes of problem identification, solution identification, proposal drafting, ratification, implementation or evaluation.

One challenge to maturing our practices for democratic engagement in governance, rather than only improving turnout on Election Day, is the recognition that at each stage of the law and policymaking process, there are distinct information needs and participation opportunities. CrowdLaw is the practice of using technology at each stage of the law and policymaking cycle to improve the quality and effectiveness of the resulting laws and policies through the use of big data and collective intelligence. By introducing more and more diverse opinions, ideas and information into the law and policymaking cycle, CrowdLaw has the potential to produce more legitimate and higher quality lawmaking. And it can work at any level of government and public decisionmaking, from Crowd-Constitution-making and Crowd-Legislation in parliaments, to Crowd-Policymaking and Crowd-Administration in government, and to CrowdAdjudication in the judiciary.

1. CrowdLaw draws on innovative processes and technologies and encompasses diverse forms of engagement among elected representatives, public officials, and those they represent. 
Technology offers the promise of opening how law and policymaking bodies work to new sources of expertise and opinion and making law and policymakers accountable to the public more on more than just Election Day. These technologies, especially the technologies of big data and collective intelligence, have the potential to change how institutions learn, enabling public institutions to govern with a much more granular and real-time understanding of on-the-ground conditions and in collaboration with residents whose 'bottom-up' intelligence they can now use. Governments at every level, for example, are using big data to pinpoint or predict the incidence of crime, heart attack and foodborne illness. Expert networking platforms-online directories of people and their skills-are helping to match civil servants who have the relevant expertise with those who need the know-how. And artificial intelligence is developing new promising ways to learn more about people's preferences and support through innovative tools like sentiment analysis.

1. When designed well, CrowdLaw may help governing institutions obtain more relevant facts and knowledge as well as more diverse perspectives, opinions and ideas to inform governing at each stage and may help the public exercise political will.

Expertise rooted in live experience or scientific facts is widely distributed in society. We have witnessed a shift away from credentialed experts to citizen experts in everything from restaurant reviews to medical advising. CrowdLaw provides a way to link this distributed expertise to governing. CrowdLaw portends a future in which governing is less something perpetrated upon the public than something done in collaboration with citizens, enabling them to actively participate. At each stage, from problem-identification to evaluation, improving outcomes may call for obtaining information and ideas in addition to gauging opinions. Both are important but require different designs to accomplish.

1. When designed well, CrowdLaw may help democratic institutions build trust and the public to play a more active role in their communities and strengthen both active citizenship and democratic culture.

With rates of trust in government at all-time lows, the legitimacy and quality of traditional representative models of lawmaking, typically dominated by political party agendas and conducted by professional staff and politicians working behind largely closed doors, are called into question. The right to vote for representatives is a necessary condition for democracy but annual elections are not going to be enough. Citizens must play a more active role in the machinery of 
governing and CrowdLaw allows this.

1. When designed well, CrowdLaw may enable engagement that is thoughtful, inclusive, informed but also efficient, manageable and sustainable.

There is much debate over the relevance of citizens doing more than voting, especially when complex decisions should be made rapidly. But CrowdLaw demonstrates that the democratic value of participation can be preserved as the same time as institutions can obtain more, better and faster expertise. However, CrowdLaw is still in its infancy. Practices differ. Legislatures, governments and public institutions organize some efforts, while others are undertaken by NGOs. Some are institutionalized with a legal mandate, as CrowdLaw requires, others are still informal.

1. Therefore, governing institutions at every level should experiment and iterate with CrowdLaw initiatives in order to create formal processes for diverse members of society to participate in order to improve the legitimacy of decisionmaking, strengthen public trust and produce better outcomes.

Despite CrowdLaw's promise, it is not self-evident that more public participation per se produces wiser or more just laws. There are countless instances to the contrary, including notable recent plebiscites. Rather than improve the informational quality of legislation, opening up decision-making may end up empowering some more than others and enable undue influence by special interests. In this sense, it is an unknown question if these new forms of digital democracy beyond the Ballot Box-such as collaborative and participatory drafting of legislation or citizen monitoring and evaluation of legislation-can, in practice, enhance the quality of the lawmaking process. To counter these risks and realize the benefits of CrowdLaw, there is an urgent need for systematic experimentation and assessment to inform and guide how legislatures engage with the public to collect, analyze, and use information as part of the lawmaking process. Evolving how we legislate requires knowledge of what participatory innovations work and when.

1. Governing institutions at every level should encourage research and learning about CrowdLaw and its impact on individuals, on institutions and on society.

To get beyond conventional democratic models of representation or referendum, and, above all, to improve learning by public institutions, we need a new model of academic research on the impact of technology on the workings of public institutions and how they use information to make decisions and solve problems. 
The improvement of our processes of law and policymaking has traditionally oscillated between two ideals that are sometimes regarded as pushing in opposite directions. The ideal of democratic legitimacy, which emphasizes the full inclusion of everyone's views, and the ideal of epistemic quality, which emphasizes having the best outputs. While the most common focus of attention is legitimacy, CrowdLaw research agenda is designed to also explore the impact of new techenabled processes on the quality and effectiveness of public decisions.

1. The public also has a responsibility to improve our democracy by demanding and creating opportunities to engage and then actively contributing expertise, experience, data and opinions.

Democracy is, in famous Lincoln's phrase, "the government of the people, by the people and for the people”. In essence, this means that elections belong to the people, governments belong to the people and governmental processes belong to the people. It is that simple and it is that complicated. There is no democracy without the engagement of citizens. Engagement is thus both a right and a responsibility of citizens in establishing, developing and sustaining democracy. Citizen engagement is not an abstraction; it takes tangible forms and serves particular purposes to improve people's lives. In this sense, CrowdLaw is more than just commenting or brainstorming, it creates real opportunities to engage. It is a series of practices at each stage of the law and policymaking process designed to elicit collective intelligence to inform public institutions in charge to promote those laws and policies. In addition to that, not any kind of participation is valuable, and we should not seek it for participation's sake. If, for instance, citizens participate after being misinformed or manipulated, such participation has no value. It does not bring in new information, it does not express citizens' genuine judgments and autonomous preferences, and it does not contribute to the quality of decision-making either. Thus, in order to foster the right kind of engagement and participation, CrowdLaw also cares about providing and promoting the adequate conditions of a civic and democratic culture among citizens.

1. Technologists should work collaboratively across disciplines to develop, evaluate and iterate varied, ethical and secure CrowdLaw platforms and tools, keeping in mind that different participation mechanisms will achieve different goals.

Develop a set of ethical guidelines and fair information collection practices for CrowdLaw practitioners to use on their apps and websites is fundamental to encourage the use of ethical information collection practices and ensure that the public is aware of and, where appropriate, consents to, the use of information 
it contributes as part of a CrowdLaw process. A CrowdLaw approach is, then, essentially interdisciplinary. Likewise, by creating a global, non-proprietary data standard structured to reflect the complete lifecycle of law and policymaking, we can enable public institutions around the world to publish shareable, reusable, machine readable data, to join that data with their own information, and to create tools to analyze or share that data. Because law and policymaking comprises a set of common stages, it is possible to create a data standard that works across levels of government and across cultures. A final expected outcome for the CrowdLaw movement is, thus, the creation of a data standard to benchmark engagement practices worldwide. Thus, CrowdLaw has, essentially, a global scope.

1. Governing institutions at every level should encourage collaboration across organizations and sectors to test what works and share good practices.

Building a network of public managers and officials, legal scholars, political theorists, computer scientists, platform and app makers, and activists to design, implement and evaluate new tech-enabled practices of public engagement in law and policymaking is fundamental to coalesce the nascent CrowdLaw community for mutual learning and collaboration and in support of more research in the field. An essential part of this Community is collaboration among governing institutions themselves, coming from different levels and countries.

1. Governing institutions at every level should create the legal and regulatory frameworks necessary to promote CrowdLaw and better forms of public engagement and usher in a new era of more open, participatory and effective governing.

Expanding CrowdLaw initiatives and the subsequent civic participation involves creating infrastructures and improving the legal and regulatory framework within the public sector. In this sense, building a comparative analysis of the current CrowdLaw statutes-legislation institutionalizing and mandating the use of citizen engagement in lawmaking at the local, regional and national level can be the first step to help practitioners around the world to formalize a legal framework for CrowdLaw initiatives and promote their structural institutionalization.

These are the twelve principles or statements that define CrowdLaw, as they are vindicated by its foundational Manifesto. However, the CrowdLaw movement should be open and dynamic, so these principles are all subject to evolution, amendment, or refinement. They are basically quests for experimentation, study, 
and learning. And such learning might bring the movement to re-think partly or fully some of them.

\section{Justice, Political Legitimacy, and the Quality of Lawmaking}

A central element to CrowdLaw that, as we have seen, cuts across most of its twelve principles, is the idea that citizen engagement in public decision-making processes, when such processes are properly designed and operate in the adequate conditions, count as instances of collective intelligence that contribute greatly to strengthening the quality as well as the legitimacy of the laws, policies and decisions made through them. CrowdLaw, we may say, is essentially committed to the aim of improving the quality of lawmaking. And consequently, CrowdLaw processes must be carefully designed to make such contribution to the quality of lawmaking effective and significant. But what do we mean by quality and legitimacy of lawmaking in this context? What kind of normative standard can we use to assess the quality of public decision-making? Should it be a procedural or a substantive standard? Should it relate to the notion of justice or to that of legitimacy, or they three are all independent? Which are the principles or elements comprised by such standard? These are questions of utmost complexity, and they all actually require much further investigation by CrowdLaw scholars. But in this section we will advance some preliminary considerations that will allow the reader to have at least a more concrete idea of the kind of problems that are involved when we talk about the quality of lawmaking.

Modern political and legal philosophers, since Locke and Bentham-not to mention other pre-modern thinkers-, as well as lawyers, political scientists, and politicians, have struggled for centuries to define a clear concept of quality of lawmaking. The result of all these centuries of study and debate, however, has been a great diversity of different uses and meanings that has led to significant confusion as to how identify, differentiate, and categorize the different principles or elements comprised by a standard of quality (Waldron 1999; Popelier 2000; Tamanaha 2006; Travares Almeida 2011; Xanthaki 2011; Rose-Ackerman, Egidy/Fowkes 2015). In conclusion, there is no a single view or understanding of the quality of law making that turns to be widely agreed by those who do theory of legislation or, as it is sometimes nowadays called, legisprudence. The same kind of confusion and basic disagreement can be found in other disciplines that have tried to answer similar questions about quality: for instance, the more developed and sophisticated discussion on the quality of regulation, especially around the 
concept of standards for a 'better regulation' (Ogus 1994; Baldwin/Cave 1999; Majone 1996; Majone 2001; Sunstein 2002; Weatherill 2007; Radaelli/De Francesco 2007; Gilardi 2008; Prosser 2010; Levi-Faur 2011; Ellig/Abdukadirov 2011; Dudley/Brito 2012; Ellig 2013; Coglianese 2017); or jurisprudence, when it studies the idea of quality of judicial decision-making; or democratic theory, especially when it attempts to define conditions of political legitimacy; or, finally, economic and management theory, when it tries to understand the idea of quality of managerial or economic decisions. What we can find in all these disciplines is very little agreement and lack of conceptual common ground about which elements constitute the quality of decision-making, and not because they simply focus on different areas or contexts, since the problems they deal with are largely the same. Perhaps more surprisingly, there has been very little interdisciplinary dialogue about this issue among all these disciplines, when it is obvious that they could learn very much from each other.

Such diversity of views and standards and conceptual confusion can be found as well in the works and reports elaborated directly by parliaments, governments and agencies to try to undertake the idea of quality of lawmaking or policymaking. Among governments, many have made significant attempts in that direction, two of them having clearly led the way. First, the UK, with a more than a century-long tradition of creating parliamentary committees and commissions to find ways to improve its own legislation. These committees have made clear progress in understanding the constituents of the quality of lawmaking, but have not thrived in establishing a widely accepted approach and methodology. ${ }^{8}$ The other leading example is the US, with also a long tradition of concern about the quality of public decision-making, especially focused in policymaking and better regulation, and which has made a remarkable job during the Obama administration to modernize and enhance the quality of regulatory policies, much under the impulse of one of the academic experts on the matter, Cass Sunstein. ${ }^{9}$ Other countries that have made significant developments are Germany, Ireland, the Netherlands, or Portugal (Voermans 2009). All have made significant efforts to make progress in understanding what constitutes the quality of lawmaking, but, again, they have not managed to produce a unified view that can be universally applied.

8 For the most recent results, see the several reports prepared by the Select Committee on the Constitution of the House of Lords, like the "Report on Parliament and the Legislative Process", issued in 2004, and the report "The Legislative Process: Preparing Legislation for Parliament", issued in October 2017.

9 See, for instance, the Executive Order 13563-Improving Regulation and Regulatory Review; and Sunstein 2002. For an overview of the efforts made during the first term of the Obama Administration, see Sunstein 2013. 
From an international point of view, some organizations such as the OECD have been long trying to provide this much needed conceptual clarity and widely shared principles of the quality of legislation and regulation, which have basically taken the form of recommendations and instruments of soft-law. ${ }^{10}$ The same applies to the European Union, with more than 20 years of experience in trying to find out the traits of a quality lawmaking, remarkably including requirements such as "opening up the policy-making process to get more people and organizations involved in shaping and delivering EU policy”, or promoting “openness, accountability and responsibility for all those involved",11 as well as "promoting a culture of dialogue and participation", which is seen as necessary "to enable the legislator to be sure of the quality, and particularly the equity, of consultations leading up to major political proposals". ${ }^{12}$ It is worth mentioning all these elements, for they are actually an essential part of the aims that CrowdLaw presupposes to contribute to.

All these institutional and political efforts have undoubtedly contributed to a better understanding of the idea of quality of lawmaking and policymaking. But what you can find in all these initiatives is, again, a plurality of views and proposals, with very little agreement or conceptual common ground. Which are the diverse principles and elements of the quality of lawmaking that have been highlighted by all these scholars, parliaments, and international organizations? Many of these accounts include, among others, the following elements:

10 See OECD, Recommendation of the Council on Improving the Quality of Government Regulation [C(95)21/FINAL], Paris: OECD, 1995; OECD, Regulatory Impact Analysis: Best Practices in OECD Countries. Paris: OECD, 1997; and OCDE, Recommendation of the Council of the OECD on Regulatory Policy and Governance, Paris: OECD, 2012.

11 See the "White Paper on European Governance"-COM(2001) 428, elaborated by the European Commission in 2001, at p. 4. Such White Paper was an attempt to improve the perception of legitimacy of the European regulations by the peoples in Europe, but also a genuine commitment to reform European governance to improve the quality of its lawmaking. This precedent was followed in the same year by the publication of the Final Report of the Mandelkern Group on Better Regulation, in November 2001, which was an attempt to revolutionize the way in which the quality of regulation had been so far conceived worldwide, for instance introducing considerations about impact assessment or simplification.

12 See the Communication from the European Commission "European Governance: Better Lawmaking"-COM(2002) 275 Final, at p. 3. See also the most recent and comprehensive "Interinstitutional Agreement between the European Parliament, the Council of the European Union and the European Commission on Better Lawmaking”, of 13 April 2016. For a review of the evolution of these concepts within the EU, see Xanthaki 2001, Radaelli/De Francesco 2007 and Voermans 2009. 
- $\quad$ The openness and transparency of the decision-making process

- The accountability of decision-makers for their decisions and performance

- The inclusiveness of the process and the diversity of perspectives and voices heard

- The deliberative quality of the process

- The adequate timing in which decisions have been made

- The involvement of experts

- The implementation of an evidence-based or scientific analysis during the process, including a comparison of alternatives on the basis of a cost-benefit analysis

- The necessity and/or opportunity of the decisions in the corresponding circumstances

- The clarity and simplicity of the decisions made

- The internal coherence or consistency of the decisions

- The congruence of the decisions with the legal system or legal conformity

- The proportionality of the decisions: for instance, minimizing coercion

- The effectiveness of the decisions, that is, their ability to produce the outcomes aimed by such decisions

- The efficacy of the decisions, that is, their capacity of being effectively enforced by the authorities if people don't obey them

- The existence of an adequate ex-post impact assessment

All these are just examples of the kind of elements or principles that have been associated with the quality of lawmaking or public decision-making in general. CrowdLaw mechanisms are claimed to make significant contributions to most of such elements, although more work is needed as to how we should exactly conceptualize each of them, what exact role each should play, or what is their relative importance when compared or weighed with each other. Just to mention, as a way of clarification, a very significant distinction, it is worth noticing that these principles and elements apply to different things. Many of them apply to the process of decision-making, while others apply to the content of the decisions made. We might actually affirm that there is a central ambiguity in our discourse on the quality of lawmaking, or at least an important distinction to be made: when we talk about the quality of lawmaking we may refer to the quality of the process of lawmaking or to the quality of the results of lawmaking. This is the well-known process-result ambiguity, and we will come back to it later. In addition to that, some of these elements are ex-ante requirements that decision-makers must fulfill before or during the making of the decision, while others are conditions that should be met afterwards, sometimes even after a long time. 
But there is something even more surprisingly flawed in these traditional accounts. They very rarely mention the ideas of justice and legitimacy, even when it seems obvious, first, that many of the elements listed above are actually requirements of legitimacy, and, second, that law should always aspire to make justice. It would be certainly bizarre to say that a law could be of the highest quality and extremely unjust at the same time. This gets us back to some of the initial questions with which we opened this section. Are the quality of lawmaking and its legitimacy one and the same thing, or they are different, independent normative standards? Or is one of them part of the other? What is the role of justice in all that? We would like to end this article by clarifying the notions of justice and legitimacy and their relation to the idea of the quality of lawmaking, in order to explain, finally, how should we understand CrowdLaw's promise regarding them. We will not provide a complete account of the idea of quality of lawmaking, which is something that exceeds the possibilities of this article. But this can be seen as a necessary first step.

As we argued above, assessing the quality of something, such as lawmaking or public decision-making, presupposes the existence of a normative standard. Normative political and legal philosophy has traditionally provided two different kinds of standards to evaluate political decision-making: legitimacy and justice. ${ }^{13}$ Most contemporary political and legal philosophers-like John Rawls, Jürgen Habermas, Ronald Dworkin, Joseph Raz, Philip Pettit, Thomas Christiano, etc.-endorse such distinction and divide the realm of political philosophy into these two areas of discussion: the theory of justice and the theory of legitimacy (Rawls 1995; Habermas 1995; Dworkin,2011). They are, therefore, the obvious standards to look at when we ask about the quality of public decision-making.

The exact distinction between justice and legitimacy is, of course, controversial. To capture the largest common ground among experts and scholars in their discussions about them, we might say that these two theories respond to two different sets of questions, in a sort of division of labor. The theory of justice provides a response to the question of what is the substantive content that laws and public decisions should have to respect the values of political morality. The standard of justice, therefore, allows us to assess the substance of those laws and decisions, regardless of other considerations, like for instance the procedural ones. The theory of legitimacy, on the other hand, answers the intertwined questions of who and how should make those laws and public decisions. In other words, who has

13 Cfr., for instance, Christiano, Thomas, "Authority", in The Stanford Encyclopaedia of Philosophy, ed. E. N. Zalta, 2013, URL: https://plato.stanford.edu/entries/authority; with Miller, David, "Justice", in The Stanford Encyclopaedia of Philosophy, ed. E. N. Zalta, 2017, URL: https://plato.stanford.edu/entries/justice. 
the right to rule over us and in what conditions. With a standard of legitimacy, we are able to assess the lawmaking processes, with certain independence from the content of the laws produced by and through them (Martí 2017; Thomas 2008; Green 2012; Edmundson 2004; Dagger/Lefkowitz 2007). These two standards, one fundamentally substantive, the other fundamentally procedural, are usually presented as partially independent, in the sense that a law may be just and illegitimate, or legitimate and unjust. ${ }^{14}$

That justice is relevant for the assessment of the quality of lawmaking is selfevident. We all care about the content of the laws we are subject to. The law is essentially coercive. And such coercion must be justifiable, especially to those on which such coercion is exerted. The problem is that we disagree too widely about what justice requires. Despite the existence of some consensus about the value of some basic requirements of justice, such as respect for human rights, our societies are characterized by the fact of pervasive, deep and wide disagreements. Different people argue for different theories of justice-namely, utilitarianism, egalitarian liberalism, libertarianism, republicanism, feminism, communitarianism, Marxism, etc. - , and disagree too widely about what the content of the laws should be. All this substantive disagreement gives us a powerful reason to turn into a less controversial standard, one that focuses in the procedural aspects of lawmaking without presupposing any particular theory of justice. In other words, given that we do not agree on the substance of what should be decided, let us at least agree on the rules of the game that will produce legitimate, acceptable decisions even if some of us happen to find them unjust.

On the other hand, even if we agreed entirely on what justice requires and what should be the content of our laws, we would still care about who and how is making those laws. ${ }^{15}$ Thus, political legitimacy is also obviously relevant for

14 This does not presuppose that they are totally independent from each other. To begin with, the set of abstract values of political morality that ground these two respective standards is necessarily the same (typically, values such as liberty or autonomy, political equality, dignity, self-respect, etc.). And second, even if legitimacy is fundamentally procedural, some scholars (like Rawls, Habermas, and Dworkin, among others) are willing to introduce some substantive constraints in it. Legitimacy itself, they argue, requires general respect for basic human rights as well. Thus, a decision that meets all the procedural requirements of legitimacy but seriously violates basic human rights would not be considered legitimate.

15 Think on the comparable case at the individual level. We generally do not like others to make decisions on our life in our name. One reason why we do not like that is that we do not need to trust others when they say that they will make those decisions in our interest. How can we know for sure? What if they just try to make a decision in our name but in their interest, not in ours? Even if we presuppose that the others are fully well-intentioned and will try honestly to make the best decision in our interest, even if we actually agree entirely with the substantive standards the 
assessing the quality of lawmaking. Political legitimacy is usually associated to democracy. Who has the right to rule over us, and in what conditions? For those who believe in self-government, the answer can only be 'us': the people. This is of course compatible with the idea of delegating power to some representatives and to some bodies and institutions operating in a complex system of division of powers and checks and balances, insofar as citizens keep effective means of ultimate control over what such representatives and institutions do and decide (Pettit 2012). All this is a well-known story. Political legitimacy, on the other hand, is not safe from the fact of disagreement. Different democratic theories compete for identifying the most adequate standard of democratic legitimacy and the concrete requirements that derive from it: representative vs. participatory views of democracy, aggregative vs. deliberative ones, consensualist vs. pluralist, radical, or agonist ones, etc. If we want to understand better how such legitimacy of lawmaking works, we will need to dig deeper into democratic theory. We cannot enter here into a detailed discussion of any of these theories, even if, as we argued in section 2, the most congenial democratic theory with the idea of CrowdLaw is the epistemic theory of deliberative, participatory democracy. It is enough, for now, by saying that our law and policymaking processes will be legitimate insofar as they are democratic. The more democratic they are, the more legitimate they can be. And there is sufficient minimal agreement about the kind of principles that can be used to measure such degree of political legitimacy. ${ }^{16}$

Thus, as we have argued, justice and legitimacy seem to be crucial for any complex standard of quality of lawmaking. It seems natural to assume that legitimacy will be at least part of the standard that will measure the quality of the process of lawmaking, while justice will necessarily play a role, if any, in the assessment of the quality of the results of lawmaking. We need to know much more

\footnotetext{
will apply in the decision-making process, we like to make our own decisions-or at least to have some ultimate control over those who make decisions in our name. Only if we are able to make our own decisions -or delegate them, if want to, but keeping ultimate control-we can have an autonomous life. Think on well-intentioned parents making (or trying to make) decisions on the life of their adult children. Even if the children agree on the standards the parents will apply, they will find that patronizing and incompatible with living an autonomous life.

16 An example can be found in the existing democratic rankings-such as The Democracy Index elaborated by The Economist Intelligence Unit-(see https://www.eiu.com/topic/democracyindex), which are good proxies to learn what countries have more legitimate political regimes than others. That does not mean that those on top are perfectly legitimate-democratic legitimacy is a regulative ideal-, or that their lawmaking has the highest quality. As we will see, there is more to the quality of lawmaking than democratic legitimacy, even if the latter is a central requirement of the former.
} 
about the exact way in which they do so. But we can extract three initial important lessons from this brief detour to political philosophy.

First of all, political legitimacy is, in effect, an essential part of the quality of the process of lawmaking. As a matter of fact, many of the principles and elements of quality of lawmaking highlighted by the literatures and listed above match many of the principles of democratic legitimacy: i.e., the openness, transparency, inclusiveness, deliberativeness, and accountability of the process, among others. However, it is not clear whether political legitimacy exhausts all the considerations that are relevant to such standard of quality of the process of lawmaking. It is certainly part of it, but not necessarily the whole of it. In any case, if we want to grasp a fine-grained understanding of the quality of lawmaking, we should start paying attention to what political philosophy has said about the ideal of political legitimacy. CrowdLaw's promise is that CrowdLaw mechanisms can enhance the political legitimacy of our decisions, and, eventually, the quality of the other procedural elements unrelated to such legitimacy.

Second, insofar as the quality of the results of lawmaking is concerned, justice should also be the first standard to take into account. However, given the fact of deep and pervasive disagreement about justice, we cannot strongly-let alone exclusively-base our quality assessment in a full-fledged standard of justice. This has two implications. On the one hand, other principles or elements of the quality of the results, such as the legal conformity or congruence of the decisions with the rest of the legal system, the clarity and simplicity of such decisions, their necessity or opportunity, or their effectiveness, efficacy and efficiency, are needed and must probably have a more central role. CrowdLaw also claims to be able to strengthen the results of lawmaking and public decision-making in relation to many of these other elements of quality. It, for instance, claims that, when properly designed, CrowdLaw mechanisms may decisively contribute to make public decisions clearer and simpler, more widely accepted, and therefore more effective and efficacious, etc.

On the other, this does not mean, anyway, that we should give up entirely the aspiration that justice plays some role in the quality assessment of the results of lawmaking. We still should want those decisions to be substantively correctand not only legally valid, or consistent, or clear and simple. And not all areas of the theory of justice are equally controversial and matter of wide disagreement. There is widespread substantial agreement, for instance, about some basic values of justice, such as freedom, equality, human dignity, and about a derivative duty of respect for human rights. Thus, the quality of the results of lawmaking-the substantive quality of the laws, regulations and other public decisions made-should also depend, significantly, on whether they meet some minimal, widely agreed requirements of justice. Which exactly are those minimal requirements of justice is 
another question that we cannot answer here. ${ }^{17}$ But, again, it is important to notice that, as we say in the last section, CrowdLaw is committed to the idea of collective intelligence and the epistemic value of deliberative, participatory mechanisms of citizen engagement. Accordingly, it claims that CrowdLaw mechanisms are better suited, first, to identify the substantive standard of correctness of public decisions, and, second, to make such public decisions respect that standard.

Finally, even if we agree that the quality of lawmaking should be bifurcated in at least two different standards of quality, one that applies to the process of lawmaking and one that applies to the results (outcomes and outputs) of such process, and even accepting the two previous conclusions regarding the role of political legitimacy and justice in such a complex standard, a lot of more conceptual work is needed to identify in detail which are the principles or elements of each standard of quality, how they relate and weigh compared to each other, and, more importantly, how can exactly CrowdLaw deliver what it promises, that is, how can it contribute to enhancing or strengthening the quality of lawmaking and public decision-making in general. All these questions, and many more, are fair doubts that remain unresolved. And they fall very far from the reach and possibilities of an article like this. But they constitute some of the main points to by covered by a future agenda of the CrowdLaw movement. The movement is just born. And it deserves a chance to do a good job in the future in making progress in our understanding of all these tremendously complex issues.

\section{References}

Bartlett, J. (2018), The People vs. Tech. How the Internet Is Killing Democracy (And How We Save (t),

Baldwin, R./M. Cave (1999), Understanding Regulation, Oxford

Benkler, Y. (2006), The Wealth of Networks: How Social Production Transforms Markets and Freedom, New Haven

- (2011), The Penguin and the Leviathan. How Cooperation Triumphs over Self-Interest, Bennett, L./A. Segerberg (2012), The Logic of Connective Action, in: Information, Communication and Society 15, 739-768

Besson, S./J. M. Martí (2006) (eds.), Deliberative Democracy and Its Discontents. National and Post-national Challenges, London

17 To make things even more complex at a conceptual level, some scholars include these minimal requirements of substantive justice, such as respect for basic human rights as a necessary condition for political legitimacy. All this show how urgent it is that we achieve some widely accepted agreement about the use of all these concepts. 
Bohman, J./W. Rehg (1997) (eds.), Deliberative Democracy. Essays on Reason and Politics, Cambridge/MA

Castells, M. (2012), Networks of Outrage and Hope: Social Movements in the Internet Age, London

Coglianese, C. (2017), The Challenge of Regulatory Excellence, in: Coglianese, C. (ed.), Achieving Regulatory Excellence, ???, 1-20

Green, L. (2012), Legal Obligation and Authority, in: The Stanford Encyclopedia of Philosophy, ed. E. N. Zalta, URL: https://plato.stanford.edu/entries/legal-obligation

Dagger, R./D. Lefkowitz (2007), Political Obligation, in: The Stanford Encyclopaedia of Philosophy, ed. E. N. Zalta, URL: https://plato.stanford.edu/entries/political-obligation

Dudley, S. E./J. Brito (2012), Regulation: A Primer, 2nd ed., Arlington, Mercatus Center at George Mason University and George Washington University Regulatory Studies Center

Dworkin, R. (2011), Justice for Hedgehogs, Cambridge, 321-323, and ch. 18

Edmundson, W. (2004), State of the Art: The Duty to Obey the Law, in: Legal Theory 10, 215-259

Ellig, J./S. Abdukadirov (2011), Regulatory Analysis and Regulatory Reform, in: Mercatus on Policy, Arlington, Mercatus Center at George Mason University, URL: https://www.mercatus.org/ system/files/ellig_abdukadirov_Regulatory_Analysis.pdf

- (2013), Ten Principles for a Better Regulation, in: Mercatus on Policy, Arlington, Mercatus Center at George Mason University, URL: https://www.mercatus.org/system/files/Ellig_ 10RegPrinciples_v1.pdf

Elster, J. (1998) (ed.), Deliberative Democracy, Cambridge

Estlund, D. (2007), Democratic Authority. A Philosophical Framework, Princeton

Foa, R. S./Y. Mounk (2016), The Democratic Disconnect, in: Journal of Democracy 27, 5-17

Fung, A. (2018), Saving Democracy From Ourselves: Democracy as a Tragedy of the Commons, Harvard University

Gilardi, F. (2018), Delegation in the Regulatory State. Independent Regulatory Agencies in Western Europe,

Habermas, J. (1995), Reconciliation through the Public Use of Reason: Remarks on John Rawls Political Liberalism, in: Journal of Philosophy 92, 109-131

- (1989[1962]), Strukturwandel der öffentlicheit, Darmstadt (The Structural Transformation of the Public Sphere, trad. Th. Burger, Cambridge/MA)

- (1996[1992]), Faktizität und Geltung, Frankfurt, (Between Facts and Norms. Contributions to a Discourse Theory of Law and Democracy, transl. by William Rehg, Cambridge/MA)

Landemore, H. (2012), Democratic Reason. Politics, Collective Intelligence, and the Rule of the Many, Princeton

Levi-Faur, D. (2011) (ed.), Handbook on the Politics of Regulation,

Majone, G. (1996), Regulatory Legitimacy, in: Majone, G. (ed.), Regulating Europe, London-New York, 284-302

- (2001), Regulatory Legitimacy in the United States and the European Union, in: Majone, G., The Federal Vision, Oxford, 252-274

Martí, J. L. (2017), Democratic Legitimacy and the Sources of International Law, in: Besson, S./J. d'Aspremont (eds.), Oxford Handbook on the Sources of International Law, Oxford, 724-748

- (2006), La república deliberativa. Una teoría de la democracia, Madrid

- (2006), The Epistemic Conception of Deliberative Democracy Defended, in: Besson, S./J. L. Martí, Deliberative Democracy and Its Discontents,

Mounk, Y. (2018), The People vs. Democracy. Why Our Freedom Is in Danger and How to Save It?, Cambridge/MA

Morozov, E.(2011), The Net Delusion. The Dark Side of Internet Freedom, New York 
Noveck, B. S. (2015), Smart Citizens, Smarter State: The Technologies of Expertise and the Future of Governing,

- (2009), Wikigovernment. How Technology Can Make the Government Better, Democracy Stronger and Citizens More Powerful,

-/G. Capone et al. (2017), CrowdLaw: Online Participation, Lawmaking GovLab White Paper, URL: https://crowd.law/table-of-contents-a34949e1ca24

Ogus, A.(1994), Regulation: Legal Form and Economic Theory, Oxford

Parkinson, J./J. Mansbridge (2012 (eds.), Deliverative Systems, Cambridge

Popelier, P. (2000), Legal Certainty and Principles of Proper Law Making, in: European Journal of Law Reform 2, 321-342

Prosser, T. (2010), The Regulatory Enterprise: Government, Regulation, and Legitimacy, Oxford

Putnam, R./B. Alone (2000)m, The Collapse and Revival of American Community, New York, ch. 2 and 21

Radaelli, C./F. De Francesco (2007), Indicators of Regulatory Quality, in: Kirkpatrick, C./D. Parker (eds.), Regulatory Impact Assessment: Towards Better Regulation?, Cheltenham, 36-55

- (2007), Regulatory Quality in Europe: Concepts, Measures and Policy Processes, Manchester

Rawls, J. (1995), Reply to Habermas, in: Journal of Philosophy 92, 132-180

Sunstein, C.(2002), The Cost-Benefit State: The Future of Regulatory Protection, Chicago

- (2006), Infotopia. How Many Minds Produce Knowledge, Oxford

- (2013), Simpler. The Future of Government, New York

-/H. Reid (2014), Wiser. Getting beyond Grougthink to Make Groups Smarter,

Tamanaha, B. (2006), Law as Means to an End, New York

Travares Almeida, M. (2011) (ed.), Quality of Legislation, Baden-Baden

Tufekci, Z. (2017), Twitter and Tear Gas: The Power and Fragility of Networked Protest, New Haven

Voermans, W. J. M. (2009), Concern about the Quality of EU Legislation: What Kind of Problem, by What Kind of Standards?, in: Erasmus Law Review 2, 59-95, at fn. 2

Waldron, J. (1999), The Dignity of Legislation, Cambridge

Weatherill, S. (2007) (ed.), Better Regulation, Oxford

Xanthaki, H. (2015), Quality of Legislation: An Achievable Universal Concept or a Utopian Pursuit?, in: Travares Almeida, M. (ed.), Quality of Legislation, op. cit. 75-85; or: Rose-Ackerman, S./S. Egidy/J. Fowkes (2015), Due Process of Lawmaking: The United States, South Africa, Germany, and the European Union, New York

Xanthaki, H. (2001), The Problem of Quality in EU Legislation; What on Earth is Really Wrong?, in: Common Market Law Review 38,

Zittrain, J. (2008), The Future of the Internet. And How to Stop It, New Haven 